\title{
Rising to the therapeutic challenge of head and neck cancer
}

\author{
Jane de Lartigue, $\mathrm{PhD}$
}

A

$s$ a significant cause of cancer-related mortality, head and neck cancer presents an

important therapeutic challenge that has proven relatively resistant to attempts to improve patient outcomes over the past several decades. In recent years, molecular profiling of head and neck cancers has provided greater insight into their significant genetic heterogeneity, creating potential opportunities for novel therapies. Here, we discuss the most promising advances.

\section{Limited progress in HNSCC treatment}

Cancers of the nasal cavity, sinuses, mouth, lips, salivary glands, throat, and larynx, collectively called head and neck cancers, are the sixth leading cause of cancer-related death worldwide. The majority of head and neck cancer arises in the epithelial cells that line the mucosal surfaces of the head and neck and is known as squamous cell carcinoma (HNSCC).

If caught in the early stages, HNSCC has a high cure rate with single-modality treatment with either surgery or radiation therapy (RT). ${ }^{1}$ However, a substantial proportion of patients present with advanced disease that requires multimodality therapy and has significantly poorer outcomes. Locally advanced HNSCC is typically treated with various combinations of surgery, RT, and chemotherapy and survival rates for all patients at 5 years are $40 \%-$ $60 \%$, compared with 70\%-90\% for patients with early-stage disease. ${ }^{1,3} \mathrm{Up}$ to half of locally advanced tumors relapse within the first 2 years after treatment. For patients with recurrent/metastatic disease, various chemotherapeutic regimens are available but median survival is typically less than a year. ${ }^{3-5}$

\section{EGFR and beyond: novel targeted strategies}

In recent years, the focus of research has shifted to the identification of molecularly targeted therapies as researchers have begun to unravel the mechanisms underlying the development of HNSCC. Epidermal growth factor receptor (EGFR) emerged as a promising target since the discovery of its upregulation in more than $90 \%$ of tumors and across all stages of disease. ${ }^{6,7}$ Intense research into EGFR-targeting therapies culminated in the approval of the EGFRtargeting monoclonal antibody (mAb) cetuximab in 2006 for the treatment of locally advanced disease in combination with RT and platinum-based chemotherapy, and as monotherapy. ${ }^{8}$ Cetuximab is also often used in combination with platinum-based chemotherapy in patients with recurrent/metastatic disease after it was shown that the combination improved disease control rates and increased overall survival (OS)., ${ }^{9} 10$ Despite these successes, only modest gains in survival have been achieved.

Numerous other agents targeting EGFR and other members of the EGFR family, including both $\mathrm{mAbs}$ and tyrosine kinase inhibitors, have been and continue to be evaluated in patients with HNSCC, with several in late-stage clinical testing (Table 1). The results of a phase 2 study of nimotuzumab administered concurrently with chemoradiation therapy (CRT) demonstrated that the combination is safe and effective and warrants further longterm study. ${ }^{11}$ Meanwhile, promising results have also recently been reported from 2 trials of the irreversible EGFR-HER2 inhibitor afatinib.

In a phase 2 study, afatinib showed significant efficacy in patients with HNSCC following failure of platinum-based chemotherapy, particularly when used after cetuximab failure. ${ }^{12}$ Results from the phase 3 LUX-Head \& Neck 1 trial were reported at the 2014 European Society for Molecular Oncology meeting (ESMO) and showed that afatinib improved progression-free survival (PFS), with a $20 \%$ reduction in the risk of progression, and significantly delayed deterioration of global health status and worsening of pain compared with methotrexate in the recurrent/metastatic setting. ${ }^{13}$

To address the potential for development of resistance to EGFR-targeting therapies in HNSCC, which may partly explain the limited efficacy observed to date, other nodes of this signaling pathway are also being targeted. Agents under investigation include PI3K, Akt, and mTOR inhibitors, as well as multitargeted tyrosine kinase inhibitors that block multiple pathways simultaneously. Despite promising clinical trials, none of these agents has

JCSO 2015;13:73-80. C2015 Frontline Medical Communications. DOI 10.12788/jcso.0111. 
TABLE 1 EGFR-targeting agents evaluated in HNSCC

\section{Drug}

Cetuximab (Erbitux)

Panitumumab (Vectibix) Amgen

Manufacturer

Bristol-Myers Squibb/ Eli-Lilly

\section{Description}

Chimeric monoclonal antibody targeting EGFR

Fully human monoclonal antibody targeting EGFR

Status of ongoing clinical testing in head and neck cancer (clinicaltrials.gov identifier)

FDA approved

Phase 3 in combination with RT (NCT00820248)

Various phase 2 (NCT00446446, NCT00798655, NCT01307956)

\begin{tabular}{lll} 
Zalutumumab & Genmab & $\begin{array}{c}\text { Fully human monoclonal } \\
\text { antibody targeting EGFR }\end{array}$ \\
\hline Nimotuzumab & YM Biosciences & $\begin{array}{c}\text { Chimeric monoclonal } \\
\text { antibody targeting EGFR }\end{array}$
\end{tabular}

$\begin{array}{rr}\text { Erlotinib (Tarceva) Genentech } & \begin{array}{r}\text { Reversible tyrosine kinase } \\ \text { inhibitor targeting EGFR }\end{array}\end{array}$

Phase 3 in combination with CRT (NCT00496652)

Phase 3 CRT +/- nimotuzumab (NCT01345084)

Phase 3 Post-op adjuvant concurrent CRT +/nimotuzumab (NCT00957086)

Various phase 2 (NCT01516996, NCT02041819, NCT02034968)

Phase $2 \mathrm{CT}+$ /- erlotinib in resectable HNSCC (NCT01064479)

Phase 2 in combination with IMRT and pemetrexed in secondary or primary disease (NCT00573989)

Phase 2 in combination with carboplatin, paclitaxel and cetuximab in recurrent/metastatic disease (NCT01316757)

\begin{tabular}{llc}
\hline Gefitinib (Iressa) & AstraZeneca & $\begin{array}{c}\text { Reversible tyrosine kinase } \\
\text { inhibitor targeting EGFR }\end{array}$ \\
\hline Lapatinib (Tykerb) & GlaxoSmithKline & $\begin{array}{c}\text { Dual tyrosine kinase inhibitor } \\
\text { targeting EGFR and HER2/neu }\end{array}$
\end{tabular}

Numerous completed, none ongoing

Phase 2 RT and cisplatin +/- lapatinib (NCTO1711658; TRYHARD)

Phase 2 in combination with RT for stage III/IV patients who cannot tolerate concurrent chemotherapy (NCT00490061)

Phase 2 in combination with cisplatin and RT in patients with unresected disease (NCT00387127)

Afatinib (Gilotrif) Boehringer Ingelheim Irreversible tyrosine kinase inhibitor targeting EGFR and HER2/neu

Phase 3 as maintenance therapy (NCTO1427478)

Phase 3 vs methotrexate in recurrent/metastatic disease after platinum chemotherapy (NCT01345682; LUX Head\&Neck 1)

Phase 3 vs methotrexate in recurrent/metastatic disease after platinum chemotherapy (NCT01856478; LUXHead\&Neck 3)

Phase 3 vs placebo as adjuvant therapy after CRT (NCT01345669; LUX-Head\&Neck 2)

Phase 3 vs placebo as adjuvant therapy after CRT (NCT02131155; LUX-Head\&Neck 4)

CRT, chemoradiation therapy; EGFR, epidermal growth factor receptor; FDA, Food and Drug Administration; HER2/neu, human epidermal growth factor receptor 2; IMRT, intensity modulated radiation therapy; $R T$, radiation therapy

been introduced into clinical practice as yet.

A range of other therapeutic strategies has been evaluated in HNSCC (Table 2, Figure 1). Mutations in the cyclin-dependent kinase gene, $C D K N 2 A$, are frequently detected in HNSCC. Loss of $C D K N 2 A$ can drive overexpression of CDK4 and CDK6, which may make head and neck tumors sensitive to pharmacological inhibition of these proteins, thus several CDK inhibitors have been evaluated in HNSCC. Again there has been limited success, with only 1 agent currently being evaluated in clinical trials. The SPARK and MONARCH trials of P276-00 - an inhibitor of CDK4, 1, and 9 - have been completed but the results have not yet been reported.

The vascular endothelial growth factor receptor (VEGFR) pathway, which plays a significant role in blood vessel formation (angiogenesis) and is often co-opted by tumors to enhance the tumor blood supply, has been reported to be upregulated in up to $40 \%$ of HNSCCs. ${ }^{14}$ The VEGF-targeting $\mathrm{mAb}$ bevacizumab is currently being evaluated in a variety of clinical trials in patients with HNSCC, including a phase 3 trial in combination with chemotherapy in recurrent/metastatic disease. 
TABLE 2 Selection of targeted therapies evaluated in HNSCC

\section{Drug}

P276-00
Manufacturer

Piramal Enterprises
Description

CDK inhibitor
Status of ongoing clinical testing in head and neck cancer (clinicaltrials.gov identifier)

Phase $2 \mathrm{MONARCH}$ trial in recurrent/metastatic disease completed (NCT00824343) - no results reported yet

Phase 1/2 SPARK trial in combination with RT completed (NCT00899054) - no results reported yet

\begin{tabular}{|c|c|c|}
\hline $\begin{array}{l}\text { Bevacizumab } \\
\text { (Avastin) }\end{array}$ & Genentech & $\begin{array}{l}\text { Humanized monoclonal } \\
\text { antibody targeting VEGF-A }\end{array}$ \\
\hline
\end{tabular}

Phase 3 in combination with chemotherapy in recurrent/ metastatic disease (NCT00588770)
Various phase 2 (NCT00703976, NCTO1588431, NCT00423930)

$\begin{array}{lll}\text { Sorafenib (Nexavar) } & \begin{array}{c}\text { Bayer Healthcare/ } \\ \text { Onyx } \\ \text { Pharmaceuticals }\end{array} & \begin{array}{c}\text { Multitargeted tyrosine kinase } \\ \text { nhibitor }\end{array} \\ \text { Sunitinib (Sutent) } & \text { Pfizer } & \begin{array}{c}\text { Multitargeted tyrosine kinase } \\ \text { inhibitor }\end{array}\end{array}$
inhibitor

Phase 2 in combination with carboplatin and paclitaxel (NCT00494182)

Phase $1 / 2$ in combination with cisplatin and docetaxel (NCT02035527)

Phase 2 alternating with cisplatin and gemcitabine as induction therapy for locally advanced nasopharyngeal carcinoma (NCT01309633)

Phase $1 \mathrm{~b}$ in combination with RT in patients with cancer, including head and neck cancer (NCT00437372)

\begin{tabular}{|c|c|c|c|}
\hline Vandetanib (Vactima) & AstraZeneca & $\begin{array}{l}\text { Tyrosine kinase inhibitor } \\
\text { targeting VEGFR, EGFR, and } \\
\text { RET kinases }\end{array}$ & $\begin{array}{l}\text { Phase } 2 \text { in preventing cancer in patients with } \\
\text { precancerous head and neck lesions (NCT01414426) }\end{array}$ \\
\hline Pazopanib (Votrient) & GlaxoSmithKline & $\begin{array}{l}\text { Tyrosine kinase inhibitor targeting } \\
\text { VEGFR, PDGFR, and c-KIT }\end{array}$ & $\begin{array}{l}\text { Phase I in combination with cetuximab for incurable } \\
\text { disease (NCT01716416) }\end{array}$ \\
\hline Axitinib (Inlyta) & Pfizer & $\begin{array}{l}\text { Tyrosine kinase inhibitor targeting } \\
\text { VEGFR, PDGFR, and c-Kit }\end{array}$ & $\begin{array}{l}\text { Phase } 2 \text { in unresectable, recurrent/metastatic disease } \\
\text { (NCTO1469546) }\end{array}$ \\
\hline Nilotinib (Tasigna) & Novartis & $\begin{array}{l}\text { Multi-targeted tyrosine kinase } \\
\text { inhibitor }\end{array}$ & $\begin{array}{l}\text { Phase } 1 \text { in combination with cetuximab in solid tumors } \\
\text { including head and neck (NCTO1871311) }\end{array}$ \\
\hline Trametinib & GlaxoSmithKline & MEK inhibitor & $\begin{array}{l}\text { Phase } 2 \text { in surgically resectable oral cavity squamous cell } \\
\text { carcinoma (NCTO1553851) }\end{array}$ \\
\hline PX866 & Oncothyreon & PI3K inhibitor & $\begin{array}{l}\text { Phase } 1 / 2 \text { in combination with cetuximab } \\
\text { (NCTO 1252628) } \\
\text { Phase } 1 / 2 \text { in combination with docetaxel } \\
\text { (NCT01204099) }\end{array}$ \\
\hline BKM120 (Buparlisib) & Novartis & PI3K inhibitor & $\begin{array}{l}\text { Phase } 2 \text { in combination with paclitaxel in recurrent/meta } \\
\text { static disease treated with platinum-based } \\
\text { chemotherapy (NCTO1852292) } \\
\text { Phase } 1 / 2 \text { in combination with cetuximab } \\
\text { (NCTO1816984) }\end{array}$ \\
\hline BYL719 & Novartis & PI3K inhibitor & $\begin{array}{l}\text { Phase } 2 \text { in recurrent/metastatic patients who failed } \\
\text { platinum-based chemotherapy (NCTO2145312) } \\
\text { Phase } 1 / 2 \text { in combination with cetuximab in recurrent/ } \\
\text { metastatic disease (NCTO1602315) }\end{array}$ \\
\hline MK2206 & Merck & Akt inhibitor & $\begin{array}{l}\text { Phase } 2 \text { in recurrent nasopharyngeal carcinoma } \\
\text { (NCT01370070) }\end{array}$ \\
\hline Everolimus (Affinitor) & Novartis & mTOR inhibitor & $\begin{array}{l}\text { Phase } 2 \text { (NCTO } 1111 \text { 1058) } \\
\text { Phase } 2 \text { in locally advanced disease (NCTO } 1 \text { 133678) }\end{array}$ \\
\hline Temsirolimus (Torisel) & Pfizer & mTOR inhibitor & $\begin{array}{l}\text { Phase } 1 \text { in combination with cetuximab in advanced solid } \\
\text { tumors including head and neck (NCTO2215720) }\end{array}$ \\
\hline LY2801653 & Eli Lilly & MET inhibitor & Phase 1 (NCT01285037) \\
\hline AZD 1775 & AstraZeneca & Weel kinase inhibitor & $\begin{array}{l}\text { Phase } 1 \text { in refractory solid tumors including head and } \\
\text { neck (NCTO1748825) } \\
\text { Phase } 2 \text { in combination with cisplatin in recurrent/ } \\
\text { metstatic disease (NCT02196168) }\end{array}$ \\
\hline
\end{tabular}

CDK, cyclin-dependent kinase; VEGF-A, vascular endothelial growth factor-A; VEGFR, vascular endothelial growth factor receptor; EGFR, epidermal growth factor receptor; PDGFR, platelet-derived growth factor receptor; PI3K, phosphatidylinositol 3-kinase; mTOR, mammalian target of rapamycin; RT, radiation therapy 


\section{Feature}

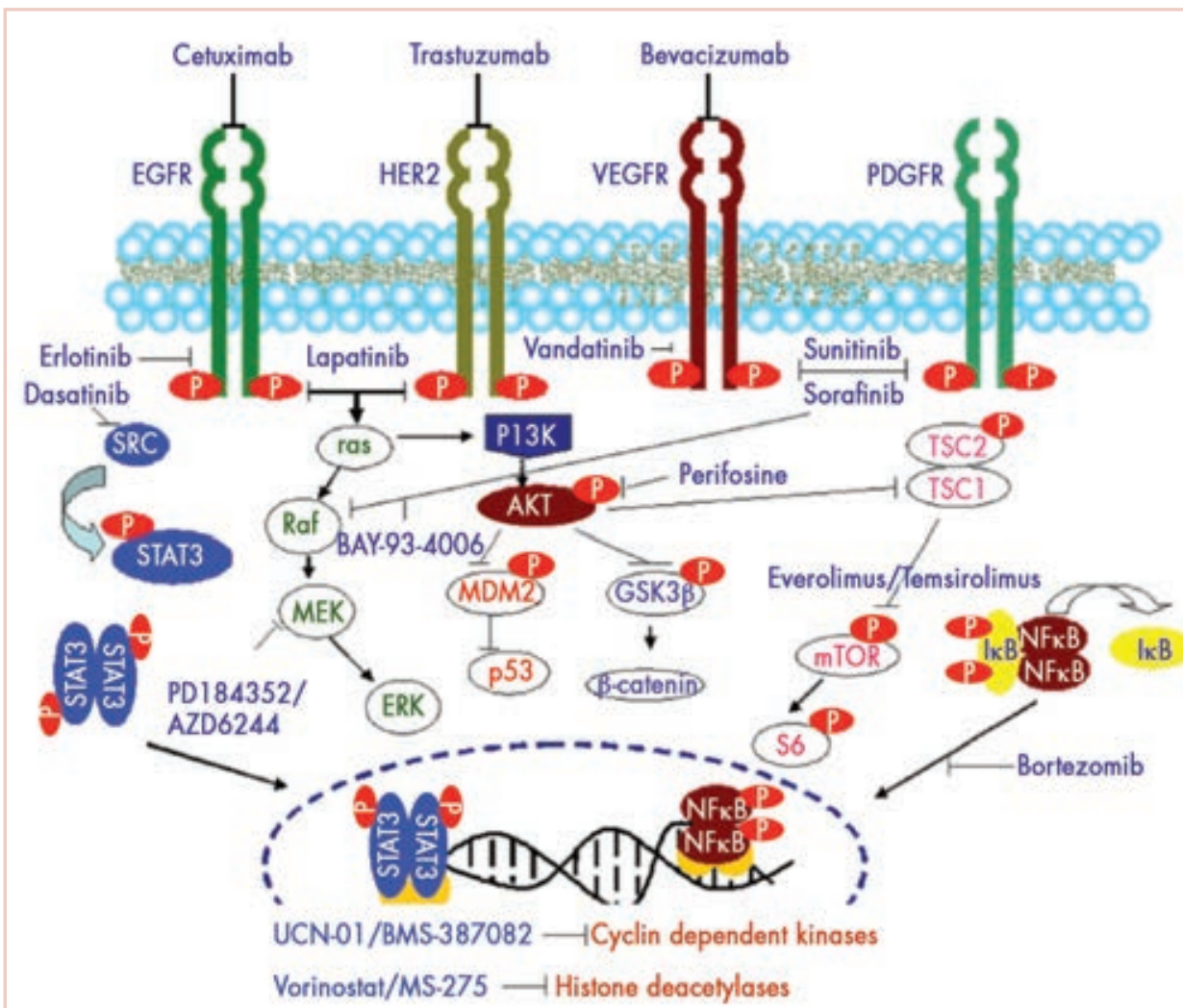

FIGURE 1 Schematic representing the signaling pathways frequently deregulated in HNSCC. Many different strategies for molecularly targeting HNSCC by blocking these pathways at various different points have been and, in some cases, continue to be evaluated. Reproduced with permission. Source: Matta A, et al. Head Neck Oncol. 2009;1:6.

HNSCC, head and neck squamous cell carcinoma

\section{Challenges of molecular targeting in HNSCC}

The development of molecularly targeted therapies in HNSCC have thus far been tempered by a poor understanding of the complex genetic background of this disease. More recently, advances in high throughput genome sequencing technology have allowed researchers to more thoroughly profile the genomic landscape of HNSCC and to identify potential novel therapeutic targets. Several key sequencing studies have been performed and are summarized in Table 3. From these studies it has become clear that HNSCCs are highly heterogeneous; characterized by a paucity of readily targetable driver mutations and frequent loss of tumor suppressor genes, which are significantly more difficult to target pharmacologically.

The tumor suppressor gene TP53 is particularly frequently associated with HNSCC and makes it substantially more difficult to treat. The p53 protein is a transcription factor that regulates the expression of a host of target genes and, as its moniker "guardian of the genome" sug-

TABLE 3 Major sequencing studies of HNSCC

\begin{tabular}{|c|c|c|c|c|c|}
\hline Study & No. of patients & $\%$ smokers & \% HPV-positive & Significantly mutated genes identified (\%) & $\begin{array}{c}\text { Mutations per MB } \\
\text { (HPV-positive/-negative) }\end{array}$ \\
\hline Stransky ${ }^{1}$ & 74 & 89 & 14 & $\begin{array}{l}\text { TP53 (62), CDKN2A (12), FAT1 (12), } \\
\text { NOTCH1 (14) }\end{array}$ & $2.28 / 4.83$ \\
\hline Pickering $^{3}$ & 40 & 78.6 & 2.5 & $\begin{array}{l}\text { TP53 (66), CASP8 (10), FAT1 (28), PIK3CA } \\
\text { (11) }\end{array}$ & Not reported \\
\hline Seiwert ${ }^{5}$ & 120 & 55 & 42.5 & $\begin{array}{l}\text { HPV-negative tumors: TP53 (81), CDKN2A } \\
\text { (21), MLL2 (1 8), CUL3 (10), NSDI (10), } \\
\text { PIK3CA (13), NOTCHI (16) } \\
\text { HPV-positive tumors: PIK3CA (22), FGFR } \\
\text { (14), NOTCH1 (12), MLL2 (10), DDX3X } \\
\text { (8), CYLD (6) }\end{array}$ & $2.46 / 2.22$ \\
\hline
\end{tabular}

Adapted from Riaz N. Genes Dis. 2014;1:75.

References: 1. Stransky N, et al. The mutational landscape of head and neck squamous cell carcinoma. Science. 2011;333:1157. 2. Agrawal N, et al. Exome sequencing of head and neck squamous cell carcinoma reveals inactivating mutations in NOTCH1. Science. 201 1;333:1 154. 3. Pickering CR, et al. Integrative genomic characterization of oral squamous cell carcinoma identifies frequent somatic drivers. Cancer Discov. 2013;3:770. 4. India Project Team of the International Cancer Genome C. Mutational landscape of gingiva-buccal oral squamous cell carcinoma reveals new recurrently mutated genes and molecular subgroups. Nat Commun. 2013;4:2873. 5. Seiwert T, et al. Integrative and comparative genomic analysis of HPV-positive and HPV-negative head and neck squamous cell carcinomas. Clin Cancer Res. 2014; Epub ahead of print. 


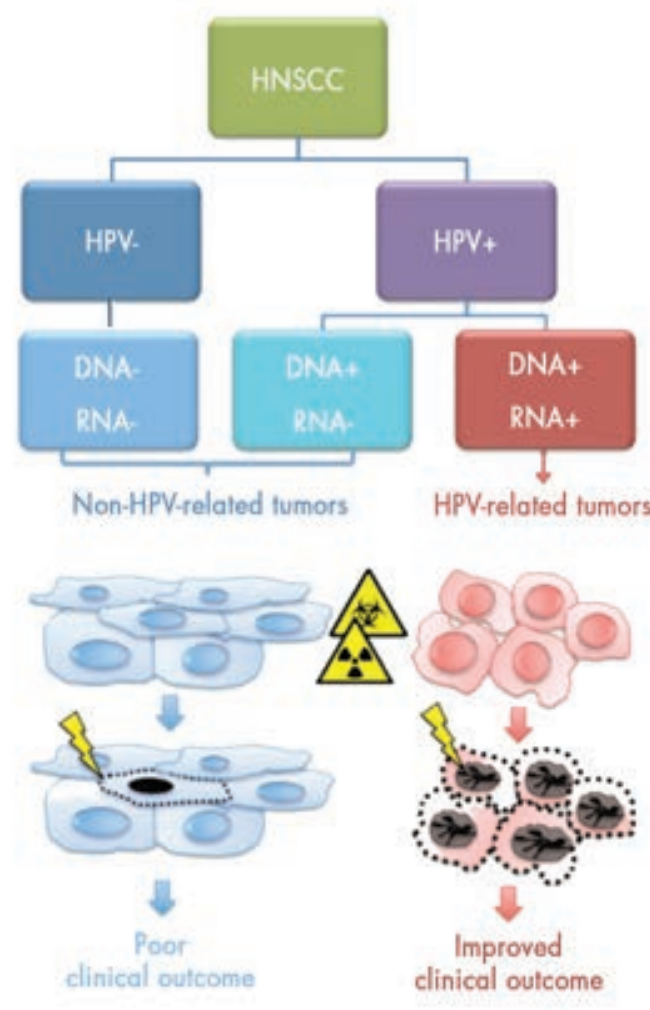

FIGURE 1 HPV-positive tumors are distinct from HPV-negative tumors in biological and clinical features, including response to radio- and chemotherapy and clinical outcome. Reproduced with permission. Source: Kostareli E, et al. Frontiers Oncol. 2012;2:36.

$\mathrm{HPV}$, human papillomavirus

gests, functions primarily to maintain the integrity of the genome. Since p53 has proven difficult to target directly researchers have turned to seeking out other genes that are specifically required for the survival of cancerous cells that contain p53 mutations so that they might indirectly target p53-mutant cancers like HNSCC.

Several research groups are taking this concept a step further and performing "functional kinomics" to identify genes that encode kinases because these are so readily druggable. Researchers have recently reported the results of such a screen in which they identified 38 candidate kinases that had an impact on the survival of p53-mutant HNSCC cell lines. Among the kinases was Wee1, which regulates the $\mathrm{G} 2 / \mathrm{M}$ transition in the cell cycle. Because $\mathrm{p} 53$ plays an important role in the G1 checkpoint, p53-mutant cancer cells may be more dependent on a functioning G2 checkpoint, thus they may be exquisitely sensitive to inhibitors of proteins like Wee1. Drugs targeting this kinase are already under development, including AZD1775. In preclinical mouse models, it inhibited the growth of p53mutant HNSCC tumors by more than $60 \%$ and up to $80 \%$ when combined with cisplatin. ${ }^{15}$ The results of a phase 1 trial of AZD1775 in patients with refractory solid tumors was reported at the 2014 American Society of Clinical Oncology meeting. There was evidence of significant antitumor efficacy in HNSCC patients with $B R C A$ mutations and accrual is ongoing in $B R C A$-positive patients. ${ }^{16}$ A phase 2 trial of AZD1775 in combination with cisplatin in patients with recurrent/metastatic HNSCC is currently enrolling patients (Table 2).

\section{$\mathrm{HPV}$ - more than a prognostic indicator}

The most significant risk factors for HNSCC are heavy exposure to alcohol, tobacco, and high-risk human papillomavirus (HPV) infection, mainly HPV-16. In recent years, the epidemiology of HNSCC has shifted considerably as a result of a reduction in tobacco consumption and a notable increase in HPV infection, such that although the overall incidence of HNSCC has decreased in developed countries over the last 30 years, the incidence of oropharyngeal cancers related to HPV infection has increased significantly. ${ }^{17-19}$

Currently, HPV-negative and HPV-positive tumors are treated in the same way. However, HPV-positive patients typically have a more favorable prognosis than do their HPV-negative counterparts - they have been shown to have a better 3-year OS rate and a more than $50 \%$ reduction in the risk of death. ${ }^{20} \mathrm{HPV}$ E6 and E7 serology in combination with $\mathrm{HPV}-16$ is most directly correlated with prognosis. ${ }^{21}$ Patients with HPV-positive tumors have also been reported to have significantly improved outcomes when treated with CRT (Figure 2).

In addition to these biological and clinical differences, a recent sequencing study highlighted the substantial genetic diversity between HPV-negative and HPV-positive tumors. Seiwert and colleagues analyzed mutations and copy number variations in 617 cancer-associated genes in 120 tumornormal pairs from HNSCC patients. Although previous sequencing studies have been dominated by HPV-negative tumor samples, HPV-positive tumors represented almost half of the total tumor samples in this study. There was no significant difference in the frequency of mutations in patients with HPV-negative compared with HPV-positive tumors, but there were very different types of genetic alterations (Table 3). HPV-negative tumors had a mutation spectrum that was similar to squamous cell lung carcinoma, with frequent mutations in TP53 and CDKN2A, whereas $\mathrm{HPV}$-positive tumors had a unique mutation profile, including mutations that were previously thought to be rare in HNSCC. ${ }^{22}$ Further characterization of the distinct mutation profiles of HPV-positive and HPV-negative tumors will be extremely important to assist in the development of targeted therapies and HPV status may become an important biomarker of treatment response. 
TABLE 4 Promising immunotherapeutic agents being evaluated in HNSCC

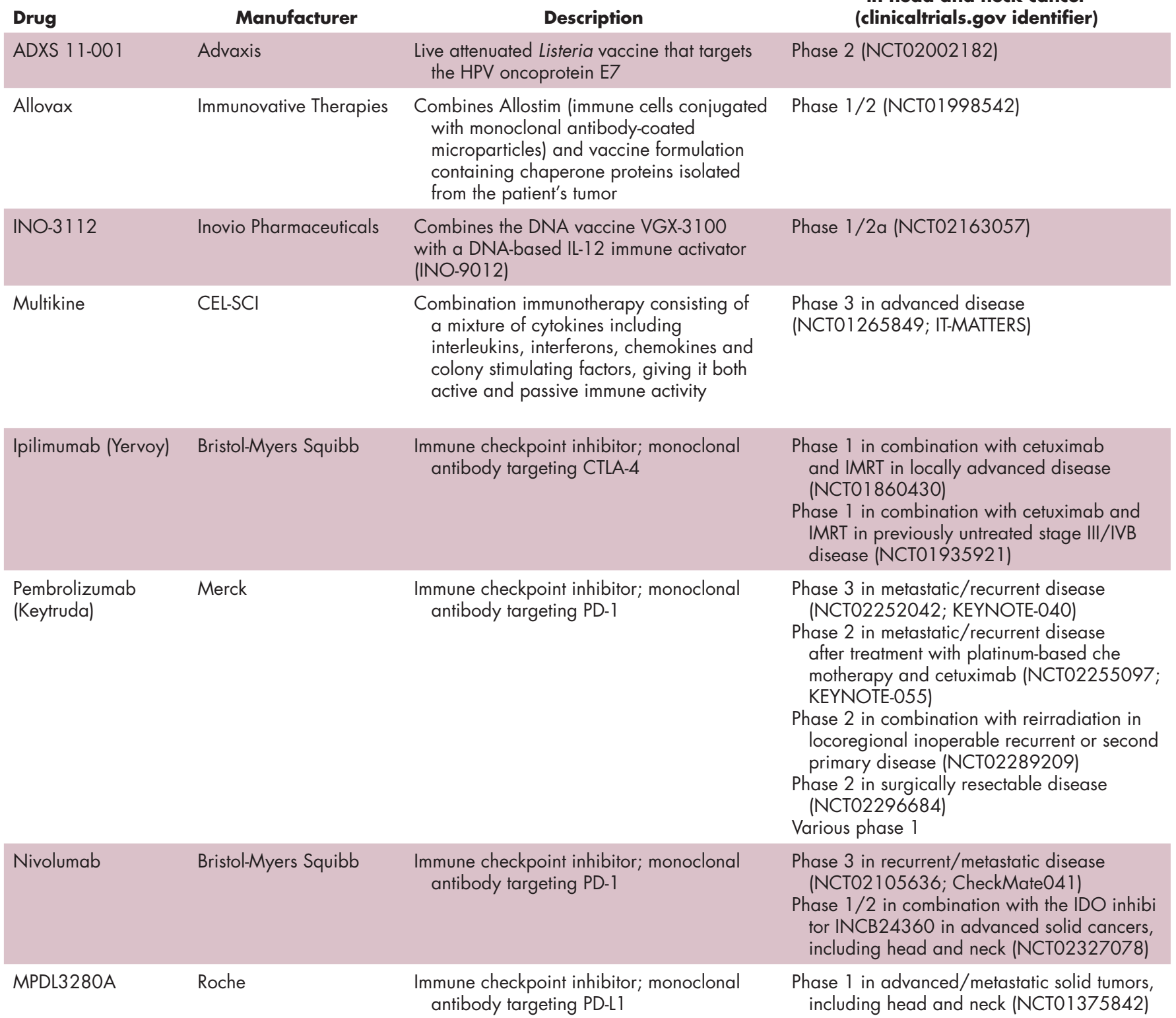

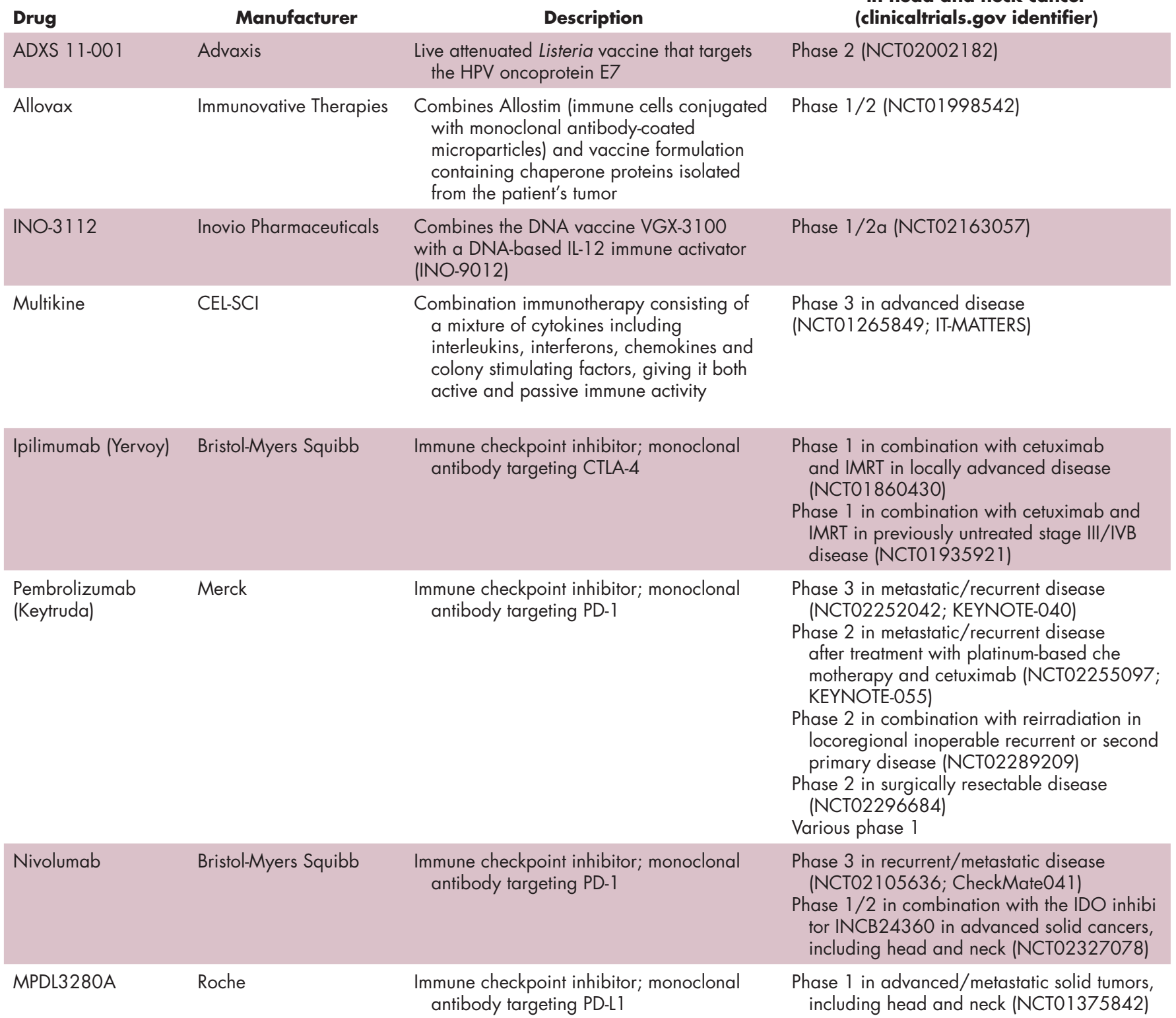

Pembrolizumab Merck (Keytruda) mune checkpoint inhibitor
antibody targeting CTLA-4

\begin{tabular}{|c|c|c|c|}
\hline Drug & Manufacturer & Description & (clinicaltrials.gov identifier) \\
\hline ADXS 11-001 & Advaxis & $\begin{array}{l}\text { Live attenuated Listeria vaccine that targets } \\
\text { the HPV oncoprotein E7 }\end{array}$ & Phase 2 (NCT02002182) \\
\hline Allovax & Immunovative Therapies & $\begin{array}{l}\text { Combines Allostim (immune cells conjugated } \\
\text { with monoclonal antibody-coated } \\
\text { microparticles) and vaccine formulation } \\
\text { containing chaperone proteins isolated } \\
\text { from the patient's tumor }\end{array}$ & Phase 1/2 (NCT01998542) \\
\hline INO-3112 & Inovio Pharmaceuticals & $\begin{array}{l}\text { Combines the DNA vaccine VGX-3100 } \\
\text { with a DNA-based IL-12 immune activator } \\
\text { (INO-9012) }\end{array}$ & Phase 1/2a (NCT02163057) \\
\hline Multikine & CEL-SCl & $\begin{array}{l}\text { Combination immunotherapy consisting of } \\
\text { a mixture of cytokines including } \\
\text { interleukins, interferons, chemokines and } \\
\text { colony stimulating factors, giving it both } \\
\text { active and passive immune activity }\end{array}$ & $\begin{array}{l}\text { Phase } 3 \text { in advanced disease } \\
\text { (NCT01265849; IT-MATTERS) }\end{array}$ \\
\hline Ipilimumab (Yervoy) & Bristol-Myers Squibb & $\begin{array}{l}\text { Immune checkpoint inhibitor; monoclonal } \\
\text { antibody targeting CTLA-4 }\end{array}$ & $\begin{array}{l}\text { Phase } 1 \text { in combination with cetuximab } \\
\text { and IMRT in locally advanced disease } \\
\text { (NCTO1860430) } \\
\text { Phase } 1 \text { in combination with cetuximab and } \\
\text { IMRT in previously untreated stage III/IVB } \\
\text { disease (NCTO1935921) }\end{array}$ \\
\hline $\begin{array}{l}\text { Pembrolizumab } \\
\text { (Keytruda) }\end{array}$ & Merck & $\begin{array}{l}\text { Immune checkpoint inhibitor; monoclonal } \\
\text { antibody targeting PD-1 }\end{array}$ & $\begin{array}{l}\text { Phase } 3 \text { in metastatic/recurrent disease } \\
\text { (NCTO2252042; KEYNOTE-040) } \\
\text { Phase } 2 \text { in metastatic/recurrent disease } \\
\text { after treatment with platinum-based che } \\
\text { motherapy and cetuximab (NCT02255097; } \\
\text { KEYNOTE-055) } \\
\text { Phase } 2 \text { in combination with reirradiation in } \\
\text { locoregional inoperable recurrent or second } \\
\text { primary disease (NCTO2289209) } \\
\text { Phase } 2 \text { in surgically resectable disease } \\
\text { (NCTO2296684) } \\
\text { Various phase 1 }\end{array}$ \\
\hline Nivolumab & Bristol-Myers Squibb & $\begin{array}{l}\text { Immune checkpoint inhibitor; monoclonal } \\
\text { antibody targeting PD-1 }\end{array}$ & $\begin{array}{l}\text { Phase } 3 \text { in recurrent/metastatic disease } \\
\text { (NCTO2 105636; CheckMate041) } \\
\text { Phase } 1 / 2 \text { in combination with the IDO inhibi } \\
\text { tor INCB24360 in advanced solid cancers, } \\
\text { including head and neck (NCTO2327078) }\end{array}$ \\
\hline MPDL3280A & Roche & $\begin{array}{l}\text { Immune checkpoint inhibitor; monoclonal } \\
\text { antibody targeting PD-L1 }\end{array}$ & $\begin{array}{l}\text { Phase } 1 \text { in advanced/metastatic solid tumors, } \\
\text { including head and neck (NCTO1375842) }\end{array}$ \\
\hline
\end{tabular}

\section{Status of ongoing clinical testing in head and neck cancer (clinicaltrials.gov identifier)}

CTLA-4, cytotoxic T lymphocyte antigen 4; IDO, indoleamine 2,3-dioxygenase; IMRT, intensity modulated radiation therapy; PD-1: programmed cell death receptor 1; PD-L1: programmed cell death ligand 1

\section{Targeting the immunosuppressive environment}

Head and neck tumors express many unique antigens that make them highly immunogenic, thus immunotherapy is a promising therapeutic strategy. A number of immunotherapies have been tested in HNSCC, including immune stimulants such as interleukins (eg, IL-2 and IL-12) and interferons (eg, IFN_), and a range of different vaccines, including dendritic cell-based vaccines, peptide-based vaccines, whole tumor vaccines, and therapeutic HPV vac- cines. Although clinical trials of several vaccines and novel immune stimulants (Table 4), are still ongoing, for the most part immunotherapy has met with disappointing results. ${ }^{23}$

More recently, our understanding of the complex interaction between the immune system and cancer has led to the discovery of numerous mechanisms of immune suppression and avoidance that are used by tumors to overcome the antitumor immune response (Figure 3). HNSCC is no exception, and these mechanisms of immune evasion 


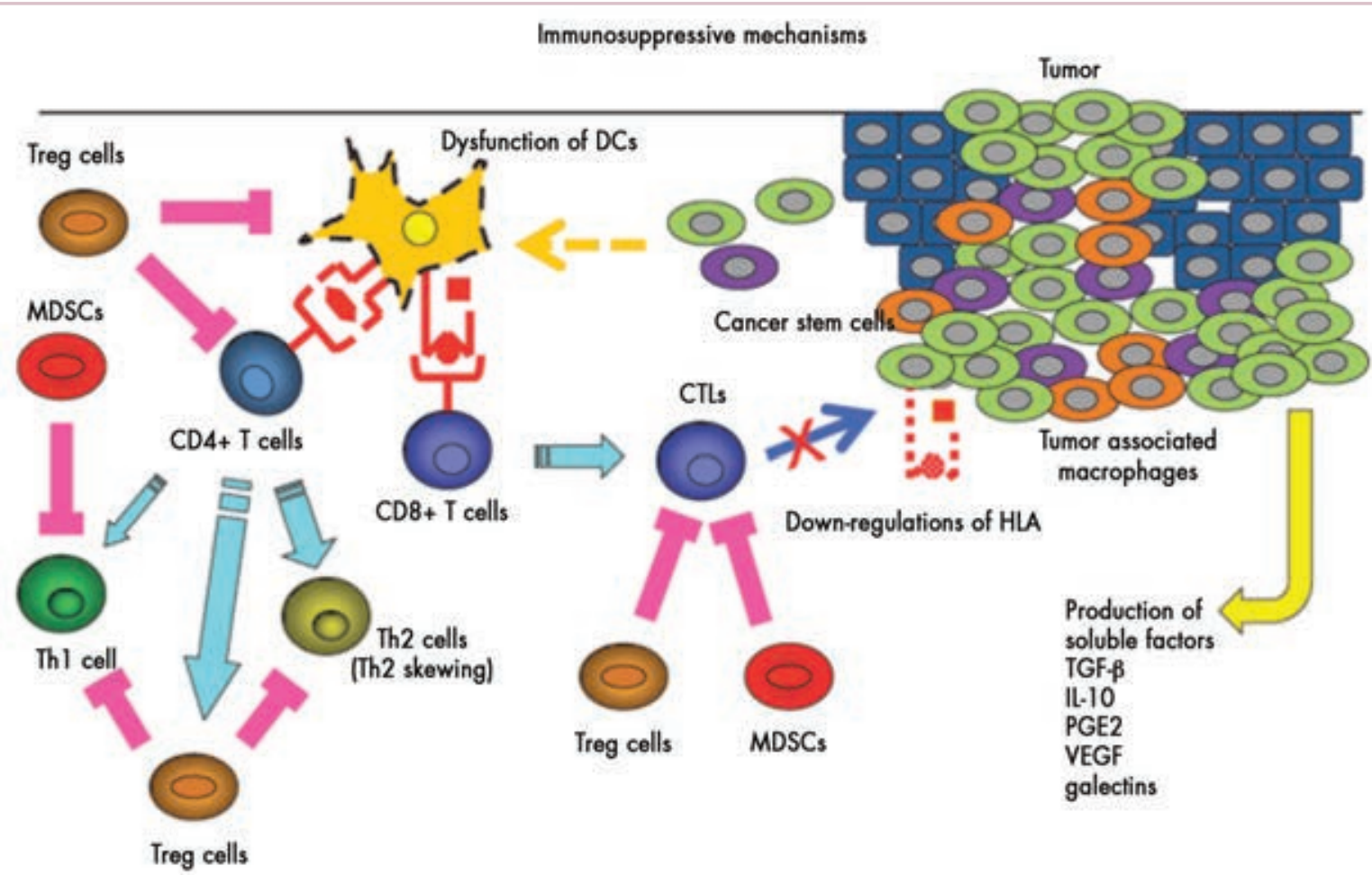

FIGURE 3 Tumors can develop a number of mechanisms to suppress antitumor immune responses, including dysfunction of dendritic cells, apoptosis of effector T cells, increased numbers of immunosuppressive cells (such as T regulatory cells and myeloid-derived suppressor cells), production of immunosuppressive molecules, downregulation of human leukocyte antigen expression, and presence of cancer stem cells. Reproduced with permission. Source: Sakakura K, et al. Cell Mol Otol. 2013;1:21809.

may partly explain the poor clinical activity of immunotherapies to date.

The fact that HNSCCs are highly immunosuppressive provides a strong rationale for testing a new class of immunotherapy - checkpoint inhibitors. These drugs are designed to inhibit the cytotoxic T-lymphocyte antigen 4 (CTLA-4) and programmed cell death receptor 1 (PD1) proteins that govern several inhibitory signaling networks, which switch off activated $\mathrm{T}$ cells at the appropriate time to maintain self-tolerance and limit collateral damage to healthy tissue. These pathways are hijacked by tumors as a means of dampening down the antitumor immune response and numerous cancer types have been shown to overexpress the PD-1 ligand PD-L1, which often correlates with poorer prognosis. Various checkpoint inhibitors are being evaluated in HNSCC patients (Table 4) and several are in late-stage clinical development.

The results of a phase $1 \mathrm{~b}$ study of pembrolizumab were presented at the 2014 ESMO meeting. In that study, pembrolizumab was tested in $61 \mathrm{HPV}$-positive and -negative HNSCC patients who expressed PD-L1. The investigators reported an overall response rate of $26 \%$, a response duration ranging from $8+$ to $41+$ weeks, and a response rate that was highly correlated with PD-L1 expression. The response rate was similar in HPV-negative and -positive patients, but PFS and OS were longer in HPV-positive patients. ${ }^{24}$

Treatment of advanced head and neck cancer remains a significant challenge, with poor response rates and substantial systemic toxicity associated with current standard of care. The search for more effective targeted therapies has proven disappointing to date, with still only a single targeted therapy approved by the US Food and Drug Administration. Improvements in sequencing technology are advancing our understanding of the significant genetic complexity and heterogeneity underlying this disease and may lead us to improvements in the HNSCC armamentarium in the near future.

\section{References}

1. Grégoire V, Lefebvre JL, Licitra L, et al. Squamous cell carcinoma of the head and neck: EHNS-ESMO-ESTRO clinical practice guidelines for diagnosis, treatment and follow-up. Ann Oncol. 2010;21(Suppl. 5):v184-186.

2. Salama JK, Seiwert TY, Vokes EE. Chemoradiotherapy for locally advanced head and neck cancer. J Clin Oncol. 2007;25:4118-4126.

3. Argiris A, Karamouzis MV, Raben D, et al. Head and neck cancer. Lancet. 2008;371:1695-1709.

4. Pignon JP, le Maitre A, Maillard E, et al. Meta-analysis of chemotherapy in head and neck cancer (MACH-NC): an update on 93 randomised trials and 17,346 patients. Radiother Oncol. 2009;92(1):4-14.

5. Brockstein BE. Management of recurrent head and neck cancer: recent progress and future directions. Drugs 2011;71(12):1551-1559.

6. Ang KK, Berkey BA, Tu X, et al. Impact of epidermal growth factor 
receptor expression on survival and pattern of relapse in patients with advanced head and neck carcinoma. Cancer Res. 2002;62:7350-7356.

7. Rubin Grandis J, Melhem MF, Gooding WE, et al. Levels of TGFalpha and EGFR protein in head and neck squamous cell carcinoma and patient survival. J Natl Cancer Inst. 1998;90:824-832.

8. Bonner JA, Harari PM, Giralt J, et al. Radiotherapy plus cetuximab for squamous-cell carcinoma of the head and neck. N Engl J Med. 2006;354:567-578.

9. Herbst RS, Arquette M, Shin DM, et al. Phase II multicenter study of the epidermal growth factor receptor antibody cetuximab and cisplatin for recurrent and refractory squamous cell carcinoma of the head and neck. J Clin Oncol. 2005;23:5578-5587.

10. Baselga J, Trigo JM, Bourhis J, et al. Phase II multicenter study of the antiepidermal growth factor receptor monoclonal antibody cetuximab in combination with platinum-based chemotherapy in patients with platinum-refractory metastatic and/or recurrent squamous cell carcinoma of the head and neck. J Clin Oncol. 2005;23:5568-5577.

11. Sundaram S, Venkatanarayanan B, Sridharan N, et al. Study of nimotuzumab with concurrent chemoradiation therapy in patients with advanced head-and-neck cancer. Int J Rad Oncol. 2014;88:493-495.

12. Seiwert TY, Fayette J, Cupissol D, et al. A randomized, phase II study of afatinib versus cetuximab in metastatic or recurrent squamous cell carcinoma of the head and neck. Ann Oncol. 2014;25:1813-1820.

13. Machiels J, Haddad RI, Fayette J, et al. Afatinib versus methotrexate (MTX) as second-line treatment for patients with recurrent and/or metastatic head and neck squamous cell carcinoma (HNSCC) who progressed after platinum-based therapy: primary efficacy results of LUX-Head \& Neck 1, a phase III trial. Presented at the European Society for Molecular Oncology Annual meeting in Madrid, Spain. September 26-30, 2014. Abstract LBA29_PR.

14. Kyzas PA, Stefanou D, Batistatou A, et al. Prognostic significance of VEGF immunohistochemical expression and tumor angiogenesis in head and neck squamous cell carcinoma. J Cancer Res Clin Oncol. 2005;131:624-630.
15. Moser R, Xu C, Kao M, et al. Functional kinomics identified candidate therapeutic targets in head and neck cancer. Clin Cancer Res. 2014;20:4274-4288

16. Do KT, Wilsker D, Balasubramanian P, et al. Phase I trial of AZD1775 (MK1775), a wee1 kinase inhibitor in patients with refractory solid tumors. J Clin Oncol. 32:5s,2014(suppl; abstr 2503).

17. Hashibe M, Brennan P, Chuang S, et al. Interaction between tobacco and alcohol use and the risk of head and neck cancer: pooled analysis in the International Head and Neck Cancer Epidemiology Consortium. Cancer Epidemiol Biomarkers Prev. 2009;18:541-550.

18. Chaturvedi AK, Anderson WF, Lortet-Tieulent J, et al. Worldwide Trends in Incidence Rates for Oral Cavity and Oropharyngeal Cancers. J Clin Oncol. 2013;31:4550-4559.

19. Chaturvedi AK, Engels EA, Anderson WF, et al. Incidence trends for human papillomavirus-related and -unrelated oral squamous cell carcinomas in the United States. J Clin Oncol. 2008;26:612-619.

20. Ang KK, Harris J, Wheeler R, et al. Human papillomavirus and survival of patients with oropharyngeal cancer. N Engl J Med. 2010;363:24-35.

21. Liang C, Marsit CJ, McClean MD, et al. Biomarkers of $\mathrm{HPV}$ in head and neck squamous cell carcinoma. Cancer Res. 2012;72:5004-5013.

22. Seiwert TY, Zuo Z, Keck MK, et al. Integrative and comparative genomic analysis of HPV-positive and HPV-negative head and neck squamous cell carcinomas [published online ahead of print July 23 2014]. Clin Cancer Res. PII clincanres.3310.2013.

23. Freiser M, Serafini P, and Weed DT. The immune system and head and neck squamous cell carcinoma: from carcinogenesis to new therapeutic opportunities. Immunol Res. 2013;57:52-69.

24. Chow LQ, Burtness B, Weiss J, et al. A phase $1 \mathrm{~b}$ study of pembrolizumab (MK-3475) in patients with human papillomavirus-positive and negative head and neck cancer [ESMO abstract LBA31]. Presented at the European Society for Molecular Oncology annual meeting in Madrid, Spain. September 26-30, 2014. 